Indeed the doctor is unlikely to find himself in agreement with many of the views expressed. Do doctors accept that they get preferential treatment in negligence actions? Or do they see themselves in a class of their own when it comes to contrasting the conditions under which they are required to work, and the standards they are required to achieve?

'It is', we read 'perhaps regrettable that the final step of prescribing treatment lies in the hands of the doctor ... However, no alternative is put forward.

Much is said about the pharmaceutical industry, but only as regards its profits and the potential harm of its products. Tighter controls and strict liability are recommended and even, if one can conceive of it, 'Independent Government controlled centres'. How many doctors accept that research and development would flourish in such a monopolistic environment?

Doctors who read the chapter on medical progress and the law may be forgiven if they conclude that therapeutic progress for the patient and legal safety for the doctor are mutually incompatible concepts.

For me, the outstanding chapter was that by Professor Ferguson-Smith on medical genetics and the law, and further references to this subject served but to highlight the essential difference between the medical and the legal approach. In the former the needs and welfare of the patient are clearly dominant, whilst repeatedly, the legal contribution seems to place legal precedence ahead of all other considerations.

Printing errors are few, but contradictions, real or apparent, occur. On page 150 we are told 'Every year many children are born in the United Kingdom suffering from congenital defects but despite advances in medical science and technology it is often impossible to pin down the major cause of such disabilities'. Three pages later we learn that 'causation is therefore comparatively simple. . $\therefore$ Again, on page 164 , on the subject of artificial insemination I read with surprise 'The doctor should say something about the donors, who they are. . : '. I had however, but to proceed to the next page to be reassured that 'The doctor will regard himself as being under an obligation not to reveal the donor's identity. . $\therefore$.

However, although there is much with which the doctor may disagree and much he may feel to have been given a one-sided presentation, this book demonstrates to him the view of the academic lawyer, a view which cannot be dismissed, remote though it may seem from the clinician's daily round.

I would recommend then the purchase of the next edition or reprint when surely the typeface must be altered. In its present form the book imposes a severe strain on retinae and resolution.

J LEAHY TAYLOR

Secretary,

Medical Protection Society,

London

\section{Shaping Tomorrow}

\section{Home Division of the Methodist Church, London \\ E1.50 (plus 50p postage)}

Public attitudes to the development of science and technology fluctuate. Two decades ago, with the marked rise in living standards and the glamour of landing men on the moon, it was one of relative euphoria. Today, in the midst of economic recession combined with inflation and the invention of smaller and more accurate nuclear weapons which has made their use more likely the public attitude has changed to one of foreboding that the development has got out of control. This report is a call for boldness in responsible risk-taking. In the first instance it is addressed to Christians, and part of it is an effort to provide a clear lay person's account of the Christian faith, how it can be held in a world of science and technology, and why it should encourage the taking of risks. The Church, it says, allowed the first Industrial Revolution to pass it by and is in danger of missing the boat again.

The report is an attempt at haute oulgarisation at the level of readers of quality newspapers, and it is very successful. It is the product of four working parties, who kept in touch with each other as they laboured for two and a half years. The first working party dealt with 'Technology of Living Things'. The main topics are human reproduction, including genetic engineering, and Man's relation to nature, with special reference to 'factory farming'. Readers of this journal are likely to need this section least. The second group dealt with 'Energy and material resources; the case of Nuclear Power'; the third with 'The Age of Electronics' (computers and microprocessors), and the fourth with 'The Social and Ethical Problems of Work and Unemployment in 'Technological Society', raising ques- tions of work, wealth and rewards. There is a glossary of technical terms, a considerable bibliography, and sets of questions for discussion.

The level of technical competence is high, and it is a useful production because few people are at home in all four areas, and indeed it is not easy to be up to date in any of them. The report is moderately written and frequently draws attention to the possibility of other points of view. It is produced in magazine format (30 centimetres $\times 20$ ), which makes it less easy than a book to keep on one's shelves; if it were a book it would be stocked by booksellers, but it is well worth the trouble of getting by post.

The names of thirty-eight collaborators are given. Of these only four are ordained and none is a moral theologian. No less than 12 come from the UK Atomic Energy Authority at Harwell and five more are employed by British Nuclear Fuels, so that it is not surprising that whereas on many issues the report raises questions but does not itself come down on one side, on nuclear fuel it comes to the firm conclusion that 'there are risks associated with the use of nuclear energy, as with everything else, but these have been very carefully evaluated, are not very big, and are not at all out of scale compared with risks of other energy sources and other ordinary hazards'. It passes too quickly over the dangers of the commercial fast breeder reactor and the permanent disposal of nuclear wastes, and it minimises other sources of energy (except coal) without drawing attention to the small amount of resources devoted to research on them as compared with nuclear energy. Nothing is said as to where work on nuclear fusion has reached.

No economist or sociologist is mentioned among the 38 names quoted. In view of this the chapter on work and unemployment is surprisingly good in its general direction but it needs to come to grips more precisely with the problems of the transition of an advanced industrial society to a service society. Also, questions of the relationship of the relatively wealthy to the poor countries crop up from time to time but are not integrated into the main discussion. There is no trace of the 'small is beautiful' point of view; I am sceptical of much of it, but it does call for evaluation.

There was only one trade unionist in this strong scientific and professional team, so it is with a smile that I read that 'relentless pressure from organised labour' made employers pay out more 
instead of less in wages after the rise in oil prices from 1973. The professional associations to which so many of the group belong did just the same! In any case, though there is some truth in the analysis it is over-simple. So, incidentally, is the remark that 'Pentecost has come again in the unlikely guise of TV'. To disentangle the truth from the error contained in it is but one instance of the stimulus to thought which the whole report provides.

PROFESSOR RONALD PRESTON

Faculty of Theology

Manchester University

\section{Psychiatric Ethics}

Eds Sidney Bloch and Paul Chodoff, Oxford University Press, Oxford £I2.50

This volume is a welcome contribution to the literature on psychiatric ethics, with papers from historical, sociological, legal and philosophical perspectives. Papers are on diagnosis, research, training in ethics, the abuse of psychiatry in the Soviet Union and suicide. There are several on particular treatments (drug therapy, sex therapy, psychotherapy and psychosurgery) and on specialties (child and forensic psychiatry). The contributors are mainly distinguished psychiatrists from the United States and England.

In their introduction the editors note that recent concern in psychiatric ethics has arisen for a variety of reasons, including the critiques of Laing and of Szasz, as well as from an awareness of the actual and potential political abuse of psychiatry. They suggest several ways in which psychiatry raises ethical issues additional to those in medical practice generally, including the deprivation of freedom for reasons of mental illness, the increased likelihood of conflict between individual and social responsibilities, and the controversial status of 'mental illness' and its diagnosis. They have organised a wide range of material in a helpful way, with repetition - difficult to avoid in a collection of this sort - kept to a tolerably low level. On the whole, the papers are excellently written and include comprehensive bibliographies.

On the other hand, it should be said that one of the main strengths of the volume is also something of a weakness. Most of the papers are by distinguished members of the psychiatric establishment, which certainly brings the benefit of authoritative and informed discussion. However, it also means that some of the pressing issues are dealt with, if not complacently, at least with little or no serious questioning of conventional psychiatric practice in America and England. Radical criticisms and proposals by psychiatrists, lawyers and others, while mentioned for the purpose of discussion, have no direct representation in the volume. Their inclusion would have served to balance the rather conservative, though by all means reasonable, views of the majority of the contributors. Connected with the general acceptance of current practice is an implicit assumption that the individual psychiatrist's conscience conforms with the demands of his professional role.

While the volume contains much discussion of ethical aspects of the relationship between psychiatrist and patient (such as informed consent), and of that between psychiatrist and third parties (such as confidentiality), there is very little examination of ethical difficulties which may arise for the individual psychiatrist in relation to the professional and institutional setting within which he works, and by which his freedom of action is implicitly and explicitly constrained. However, such shortcomings do not detract from the substantial positive achievements of the volume, which the reviewer recommends without hesitation to those involved with ethical issues in psychiatry, which includes all practising psychiatrists, and particularly to those responsible for training.

\section{DEREK BOLTON
The Bethlem Royal Hospital Beckenham Kent \\ A Philosophical Basis of Medical Practice}

\section{Edmund Pellegrino and David Thomasma Oxford University Press, New York £I I.50}

Philosophers have not, until recent times, been welcomed, much less invited to provide their conceptual and critical skills as a service to the State or to established and successful professions such as those in the area of the sciences. We need only remind ourselves of the fate of Socrates to realise that the skills of the philosopher have been judged at best as confusing and, at worst, as socially disruptive and dangerous. The philosopher is accused of having no content of his own to reflect on and viewed, therefore, as parasitic on the content of alternative disciplines for reflection. A Philosophical Basis of Medical Practice exhibits a constructive change from this traditional stereotype of the philosopher in the ever-expanding dialogue with medicine. The exchange is seen to be mutually beneficial, a welcome advance over the outmoded model of the wise philosopher unilaterally offering his insights into the meaning and purpose of human existence. Philosophy gains in the mutual exchange by gaining access to concrete, verifiable and measurable data about human life as ground for reflection and inquiry while, at the same time, medicine is urged to overcome its anti-philosophical bias and its own claims to preciosity and sacerdotal privilege. The two authors, Pellegrino and Thomasma, have brought their own expertise from medicine and philosophy to articulate the features of a philosophy of medicine and its applicability to both individual and social ethics.

What is most ambitious and impressive about the book is the attempt to provide a comprehensive conceptual framework of ontology, method and value theory within which the interfaces between philosophy and medicine cam be more clearly and systematically spelled out. The framework includes a delineation of a philosophical method to be pursued; reflection on the nature of medicine; an ontology of the body, and the anatomy of clinical judgments. A fundamental claim which is argued for throughout, and which is essential to establishing the links between philosophy and medicine, is that medicine is clearly not a value-free science. Insofar as many of the assumed factual judgments of medicine are either valueladen themselves or reveal value presuppositions, these judgments invite critical scrutiny from the philosopher. Value-laden judgments which pervade the practice of medicine are not construed as suspect in an $a$ priori manner but are made explicit in the interest of achieving greater understanding of the foundations of medical practice.

The clinical situation is analysed as a calculus of interacting variables all governed by, geared to, and reflecting the patient's need. Predictably, the patient-physician relationship comes under detailed philosophical scrutiny, a scrutiny which rejects the Hippocratic image of the physician as a paternalistic, albeit benevolent, authority in both technical and moral matters. The analysis of the nature of medicine and 